\title{
'Not in a pakeha court': Kastom and Pacific media
}

Laws which most concern journalists, such as libel, have been framed entirely within a western context. This hinders and often disbars ordinary people from seeking redress against the media in western-style courts. A personal look at ways ordinary citizens might gain satisfaction.

\section{By PHILIP CASS}

THE PROVISION of laws which apply to journalists in the Pacific has been made within the framework of western institutions and the outcomes expected in western style courts. However, the Pacific Islands are not western states and many people continue to live within very traditional societies. Post-independence constitutional guarantees of freedom of expression and legal systems were designed without the needs of those who operate within traditional, or Kastom, social frameworks in mind.

This is a serious problem, especially when ordinary people - the grassroots as they are called in PNG - are offended by malicious or foolish reporting. The Pacific media does occasionally offend and those who feel the need to seek redress are not only the rich and powerful. A way should be found to give ordinary people a means to take action against the media for such matters as libel (a western concept, but one which is reflected in ordinary notions of honour) and seek judgement and redress using customary procedures which have the same status as western inherited law. If something like this is not done, then the whole business of the law and the media will remain the preserve of a western educated and western oriented elite.

Anecdotal evidence suggests that very few genuine actions for libel ever reach court in the Pacific. Most actions for libel are initiated by governments, or politicians or public figures seeking to use the law to gag or punish the media, 102 PACIFIC JOURNALISM REVIEW 6:1 2000 
KASTOM AND THE MEDIA

rather than by ordinary citizens seeking redress for libel or incorrect reporting.

I would suggest that this is because there are very few lawyers in the Pacific and most of them charge fees which put them beyond the reach of any but the wealthy. Minimum fees that I have been quoted start at around F $\$ 1000$, which makes a mockery of the notion that the courts provide an equal chance for all citizens to seek redress.

We must also question whether the inherited western concept of going to court over a personal injury is completely appropriate to the Pacific. Kastom generally dictates that personal matters are dealt within the community or between groups using a prescribed set of rituals, which may range from compensatory exchanges of goods between individuals or more sophisticated systems in which a big man or chiefly person takes personal responsibility for the transgressions of a member of his or her group.

There is a strong feeling against sorting out personal problems in public, where "public" is conceived of as being outside the village, family group or clan. ${ }^{1}$ Some western observers would argue that individual rights are nonexistent in traditional societies. ${ }^{2}$ I would not go this far myself (and certainly Lloyd would not argue from such a rigid position), but I would argue that there is a fairly well defined and accepted pattern of individual rights being secondary to group needs, especially when it comes to maintaining harmony within a group and, perhaps more importantly, an outward appearance of harmony. Traditionally, problems are resolved within the group — the "public" — rather than by or in an outside agency. This was perhaps best summed up by a Maori journalism lecturer in Christchurch some years ago. "We settle our problems on the marai," he said. "We do not air our dirty laundry in a Pakeha court."

The inherited western notion that the tort of libel - or any personal injury - can be redressed by being debated publicly in an adversarial forum and then compensated by an order of the court clearly requires that much private business be aired publicly. Quite apart from the problem that many Pacific people may have with the notion of airing problems in a forum outside their immediate family, clan or land owning group, there is, I believe, another problem in that western law does not carry with it the notion that once an offence has been paid for, it has been negated. A conviction and an order for compensation made in a western style court means that the conviction stays on the books, is part of the public record and does not disappear.

To speak generally, Kastom allows that an offence be paid for and then negated, so that relations between the parties can be returned, as it were, to a zero 


\section{PHILIP CASS}

point before the original offence was committed. As Lloyd puts it:

The main object of sanctions...is not so much to punish the individual offender as to restore the status quo ante, that is, to maintain the social order, for the breach is regarded as disturbing social solidarity, which has then to be restored. ${ }^{3}$

This is not the same as punishment in the western sense, but a way of re-ordering the balance of the communal universe to regain stability in the community. I would suggest that settling out of court, where the two parties agree to a compensation payment in secret, is not quite the same thing. I would suggest and my discussions on this issue with my students at the University of the South Pacific would seem to confirm it - that compensation payments have to be made within the context of Kastom.

My students, who were drawn from all over the Pacific, felt that traditional methods of recompense were much more effective. Their attitude can be summarised as: "If it is done in court then they can hide it away. If you agree to pay lots of pigs to somebody then everyone in the village will know what is going on. Even if you hand over everything at night everybody will know and it will be public."

The western legalistic approach would say that the offender had not been punished by not going to a western-style court, but by using a customary system the person would suffer from the humiliation of knowing that everybody who mattered to him or her was aware of what was going on. The social sanctionand social balance - that lies at the heart of Kastom law is what makes compensatory rituals so effective. They are "public". If a case involved people from outlying islands or an isolated district and the case was heard in the capital then it would be "Public" and the people for whom the case was significant would not know. I say this because one of the values of traditional compensation systems is that they normally take on a ritualised form which is significant to the community. A secret agreement behind a lawyer's door in the capital does not have the same social meaning or significance of an open exchange of pigs, shells or tabua in the village. As one of my students at USP put it, even if the handover is done privately, everybody will know what is going on because the person making the compensation will have been making very public purchases of compensatory goods beforehand.

I do not suggest that Kastom is the only way of righting a wrong. There is 
as much bad reporting and stupidity in some sections of the Pacific media as there is anywhere in the world and when the media does wrong there should be an opportunity to take it to court and punish it publicly. However, citizens who cannot afford lawyers and who want to redress the balance rather than inflict punishment, should also have access to a system which allows them traditional remedies.

While many Pacific nations give constitutional recognition to Kastom law, it rarely has equal status with western law, and is usually not referred to except perhaps in disputes over land ownership. In some parts of Australia, Kastom law may be chosen as an option to western law, but is not regarded as superior to it. However, it is well to remember Ntumy's caution that:

Whatever the status theoretically given to custom by the constitution or other laws, it will be important in shaping the indigenous common law only to the extent that the judges of the higher courts recognise and apply it. $^{4}$

In countries with a single or dominant language, a hierarchical system of government and common traditions between different clans or land owning groups, customary laws are easy to identify. In countries with many languages, cultural practices and ethnic groups, the derivation of Kastom is more problematical. However, cultural differences are usually not as great as linguistic ones and it is possible to identify common customary law in even the most superficially fragmented societies. So, theoretically at least, it should be possible to develop Kastom-based legal systems which are acceptable across even the most superficially divergent societies.

Would it be practicable to use Kastom-based methods in a system which would allow ordinary people to have some recourse against inaccurate or hurtful reporting in the media? If we consider libel as a tort, then we can find evidence that customary procedures are already being used. In Tuvalu, for instance,

there are few if any tort actions, as disputes are resolved at communal level by resort to customary dispute settlement mechanisms such as conciliation, mediation and arbitration. ${ }^{5}$

Similarly, in Western Samoa, 


\section{PHILIP CASS}

The traditional Samoan ifoga, or public apology, is customarily offered and accepted as a means of healing relations between families where a member of one has caused harm to a member of the other. Despite the fact that money and ceremonial goods may pass between the families in the ifoga, the courts have to date, been unwilling to hold that an apology that is accepted represents full settlement of a claim of damages brought by the injured party. ${ }^{6}$

The two examples given represent situations where Kastom practices are used to avoid going to court. The media law in American Samoa appears designed to encourage people to reconcile before proceeding with court actions. American Samoa has devised a law on defamation that neatly combines inherited legal provisions for the protection of individuals with a Pacific tradition of compromise. The defamation laws are designed to keep people out of court until tempers have cooled.

A newspaper, periodical or radio or television station must be given a week to correct defamatory matter before a civil action may be commenced. A retraction is the only acceptable means of correction where the true facts are, with reasonable diligence, ascertainable with certainty. Otherwise the publication of the libelled person's statement of the facts - or so much thereof as is not libellous or another, scurrilous or otherwise improper for publication - constitutes a correction. If it appears upon trial that the publication was made under an honest mistake or misapprehension then a correction published in a timely fashion without comment in a position and type as prominent as the alleged libel or broadcast at the same time of day as the broadcast complained of and of equal duration shall constitute a defence against the recovery of any damages except actual damages. It is also competent and material in mitigation of actual damages to the extent the correction published does in fact mitigate them. ${ }^{7}$

The legislation outlined above appears designed to encourage reconciliation between the parties and to positively discourage them from making the matter "Public" by taking it to court. It is western, not Kastom legislation, but it appears designed to encourage the use of Kastom in settling disputes. Even as a piece of western style legislation, this is a remarkably generous law. Reconciliation is a feature of other courts in the Pacific. In Fiji, for instance, courts allow for reconciliation in some cases at the discretion of the magistrate. 
KASTOM AND THE MEDIA

However, even with a policy that allows for reconciliation between aggrieved parties, western style courts are expensive and, by their nature, confrontational. Perhaps what is needed is a forum to which ordinary citizens (not somebody fronting for a chief of politician) could come before a person acknowledged as being knowledgeable in Kastom, impartial and with a knowledge of the media. This would require giving Kastom law equal standing with western law and would certainly need to be handled very carefully.

I began this article with a reference to the use of courts by politicians and persons of chiefly rank against the media. I would suggest that the constant use of the courts in this way may also be seen in terms of Kastom. Libel actions against the media by Pacific governments should not just be seen as ways of muzzling press criticism (in the western sense) but especially in countries with Polynesian hierarchies (Samoa, Tonga, Fiji) of trying to re-order the natural balance of society. This use of pressure can be countered either through the courts (as witnessed by Tongan editor 'Akilisi Pohiva's constant battles) or, as reported by Layton, the use of chiefly titles by editors who can then ask questions as equals. This is a response to Kastom pressure by using Kastom as a response

In a recent article in the South Pacific Law Journal, Kenneth Brown asks whether Kastom and western laws can be synthesised or whether western laws should give equal recognition to Kastom law. ${ }^{8}$ Brown notes that stable western legal systems are the best for progress and post colonial development, but certain freedoms inherent in western legal systems such as freedom of expression are not found in traditional hierarchies and need to be protected. However, as I have argued already in this chapter, the inherited western legal system can deny ordinary people redress because of its costs and because its outcomes are not always satisfactory in terms of traditional culture and societal balance.

What I have suggested is a system which synthesises western concepts of libel with Kastom ideas about personal wrongs, but which gives equal weight (or rather equal choice) as to the possible outcome. I have argued elsewhere ${ }^{9}$ that the Pacific is very good at synthesising western and Kastom traditions. I believe this is possible because, as Brown says, Kastom law is not as rigid as it seems.

...customary law principles are flexible and adaptable and...can be applied to situations and disputes that may not have arisen in pre-modern times. ${ }^{10}$ 


\section{PHILIP CASS}

But if Kastom is susceptible to change, what about the traditional societies from which it sprang? Traditional societies in the Pacific are under constant pressure from outside influences, one of the most powerful being the media, which is why the holders of power and the media are so often at loggerheads. Now, if Kastom is all about redressing the balance, is there a Kastom for admitting the balance has tipped and welcoming change? What if, every time a person of noble or chiefly rank lost an action against a newspaper editor of equal status he had to publicly hand over 100 royal pigs? But note here that I have referred to an editor "of equal status". The idea of a commoner successfully fighting a noble in the courts is almost unthinkable.

And yet, as Layton points out, chiefs use tradition as a weapon against the media, a practice which has led some journalist to seek chiefly rank. ${ }^{11}$

Cultural mechanisms are being appropriated by journalists for the express purpose of protecting and developing the free flow of information in their societies. The active use of social status to resist government and community pressure is one such trend. In Western Samoa editors are taking matai titles to overcome the "distinction between those who direct and those who listen" (Aiavao, 1993). In Fiji, the late Ratu Sir Penaia Ganilau's daughter Adi Mei Gauna, a Fiji Broadcasting Corporation executive, likewise counsels journalists to use whatever traditional status they may possess to "exert the pressure back if it's not right".

For those who do not have access to such rank, a system which brings together western concepts of the media and media law with traditional systems of reconciliation and recompense is probably the only answer. Unfortunately it would probably only work if everybody who came before such a forum was deemed equal (as they are in western style courts) and this would require a radical shift in the application of Kastom in countries with Polynesian style hierarchies rather than the more open Melanesian Big Man system. And yet such a thing is not impossible. Kastom does not mean set in stone. Comparing western and "primitive" legal systems, Lloyd argues that traditional systems are just as flexible as "modern" ones and that they afford frameworks of recopricity within which the individual may enjoy freedom, rather than unyielding cages of unchanging custom:

Two...important misconceptions have been gradually dispelled. The first

of these was that in early society custom was completely rigid and 108 PACIFIC JOURNALISM REVIEW 6:12000 
unchanging and that primitive man was born into a helpless condition of total conformity to tribal custom. In this view the group rather than the individual was the only unit of social order...Some of these clouds have been dispelled by such investigators as Malinowski who have shown how many of the rules of a primitive society derive not from dark beliefs in and fear of the supernatural, but rather, as indeed in our own society, in the need for reciprocity in social and economic conditions. For just as our own society provides a legal and institutional basis for the regulated exchange of various services, so similar customary rules are to be found in primitive societies in order to provide the means of satisfying their economic and other needs. Moreover, these rules, far from being absolutely inflexible and unchanging are indeed, bearing in mind the vast differences between the two modes of life and the technological equipment and organisation supporting them, in a manner similar to our own legal, system, subject to a process of constant adaptation to new situations, old rules being re-interpreted and new rules being from time to time created. ${ }^{12}$

\section{Conclusion}

Everybody concerned with the media and the law in the Pacific faces a dilemma. The only way in which the media can defend itself against attacks by politicians and chiefs is by fighting and winning in western style courts. However, when the media libels or maligns somebody, the costs of court action are simply too high for anybody who is not immensely rich to seek redress. Even if an ordinary citizen was able to go to a western style court, there are many cultural barriers against fighting in "Public" and the desired outcome is not often one that can be provided in a western-style court. The laws of libel have been framed with western institutions and practices, rather than traditional ones, in mind.

Western laws are absolutely necessary to defend western style laws guaranteeing freedom of expression, but I would suggest that traditional processes of reconciliation and compensation should also be incorporated into the legal process. Kastom is accorded some status in many Island constitutions and the process of reconciliation already exists in some legislatures. The next step is to find a way of bringing the media, the law and Kastom together.

If, as Singh suggests, the future of Pacific journalism lies in adopting a more developmental approach, then surely part of that development must be to make the media more responsive to the needs of its audience in its own terms, even if those terms are traditional. ${ }^{13}$ If the laws governing the behaviour of media 


\section{PHILIP CASS}

practitioners are to be universal then they must embrace Kastom as well as western concepts of law and be as much about restoring balance to society as well as changing it.

\section{Bibliography}

Kenneth Brown (1999). "Customary law in the Pacific: An endangered species?" in Journal of South Pacific Law, III, Port Vila.

Philip Cass (1998). "I cannot photograph the adi: Self regulation and social control in a hierarchical island society". in Allen, Holmes et al (eds) Self Regulation in the Media, City University, London.

Michael Ntumy (ed) (1993). South Pacific Islands Legal Systems, University of Hawai'i Press, Honolulu.

Suzanna Layton (1995). Interview with Kalafi Moala, editor of Taimi 'o Tonga in Pacific Islands Communications Journal XVI:2, Suva.

Dennis Lloyd (1974). The Idea of Law, Pelican, London.

Debbie Singh (1998) "Press Freedom in the Pacific Islands" in Pacific Islands Monthly, Suva, January.

\section{Notes}

${ }^{1}$ We should differentiate between "public" when it involves the village or clan and "Public" when it involves the larger world.

2 "Traditional societies have no culture of individual rights. They maintain their structure and coherence through a culture of duties." Kenneth Brown, "Customary law in the Pacific: An endangered species?" in Journal of South Pacific Law III: 1999.

${ }^{3}$ Dennis Lloyd (1974). The Idea of Law, Pelican, p234. Not that the offence or the compensation is really forgotten, of course, but for the sake of social stability and face, it is deemed by members of the community to be so. Such subtleties, alas, sometimes seem beyond the grasp of western law which demands that unless a thing is seen to be done in court, it has not been done at all.

${ }^{4}$ Michael Ntumy (ed) (1993). South Pacific Islands Legal Systems, University of Hawai'i Press, Honolulu, pxxii.

${ }^{5}$ Ntumy, p361.

${ }^{6}$ Ntumy, p427.

${ }^{7}$ Ntumy, p459.

${ }^{8}$ Brown, ibid.

9 "I cannot photograph the adi: Self-regulation and social control in a hierarchical island society", in Allen, Holmes et al (eds) (1998), Self-Regulation in the Media, City University, London.

${ }^{10}$ Brown, op cit. 
${ }^{11}$ Suzanna Layton (1995), Introduction, Pacific Islands Communications Journal XVI:2, Suva.

${ }^{12}$ Lloyd, p232-33.

${ }^{13}$ Debbie Singh, "Press Freedom in the Pacific Islands" in Pacific Islands Monthly, January 1998.

University of the South Pacific's law website: www.vanuatu.usp.ac.fj

Pacific Law Journal: www.vanuatu. usp.ac.fj/sp_law_journal/Journal/journal-main.html

$\square$ Philip Cass is Principal Lecturer in Journalism at the University of Teesside in Middlesbrough, UK. He taught journalism at the University of the South Pacific from 1995-97 and before then ran a number of workshops for journalists in Papua New Guinea. Born in PNG, he has worked as a journalist and academic in Australia, Papua New Guinea, Fiji and the United Kingdom. Email: P.Cass@tees.ac.uk

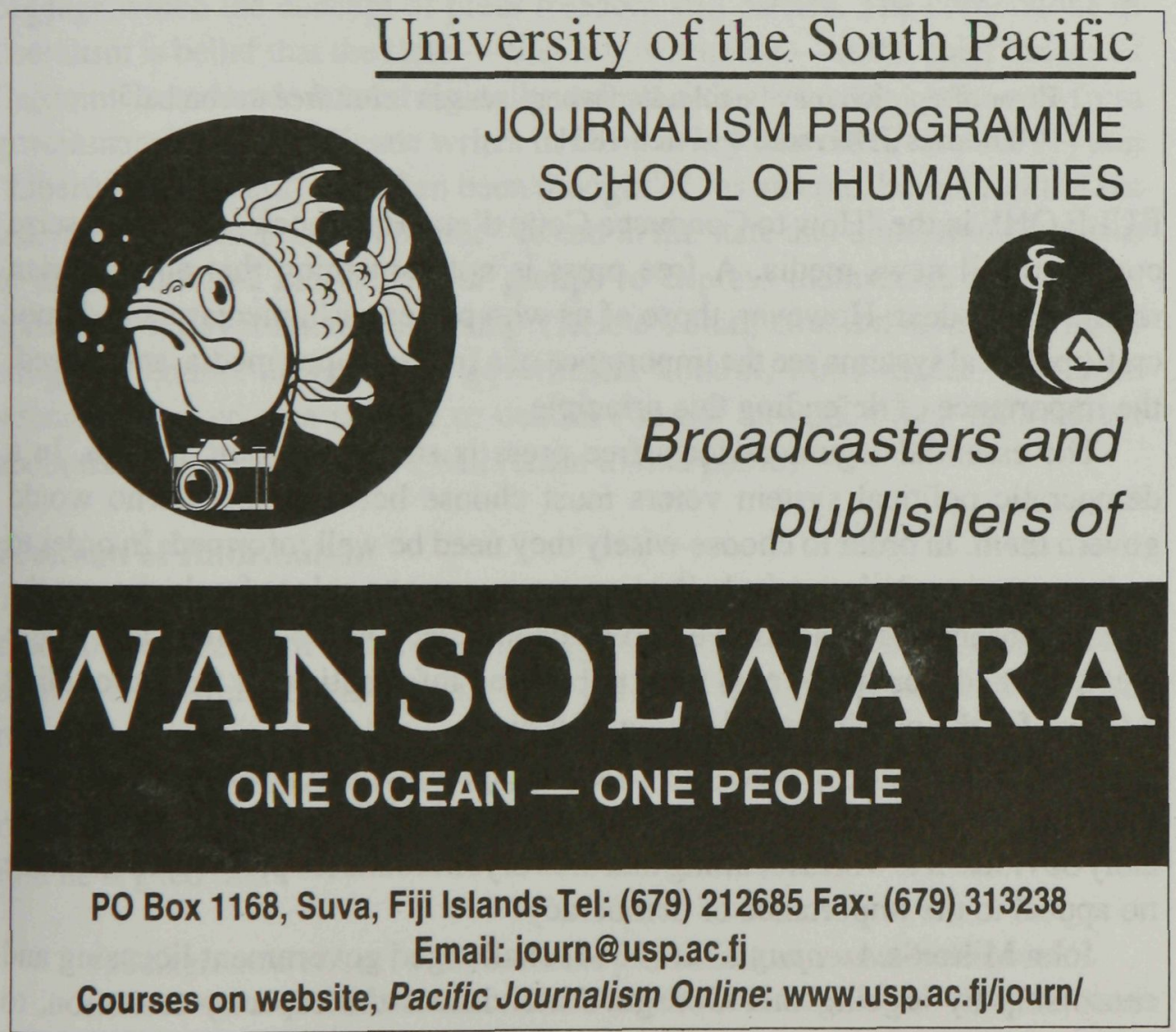

